\title{
Tea Polyphenol inhibits autophagy to sensitize Epirubicin-induced apoptosis in human bladder cancer cells
}

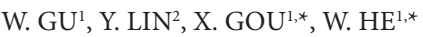 \\ ${ }^{1}$ Department of Urology, The First Affiliated Hospital of Chongqing Medical University, Chongqing 400016, China; ${ }^{2}$ Molecular Biology and Lung \\ Cancer Program, Lovelace Respiratory Research Institute, Albuquerque, NM, US \\ *Correspondence: gouxincq@163.com,weiyang361@163.com
}

Received September 25, 2016 / Accepted January 31, 2017

\begin{abstract}
Resistance to anticancer agents such as Epirubicin (EPI) becomes a great challenge for treating bladder cancer. However, the mechanism by which chemoresistance arised is still elusive. In the present study, we showed evidence that EPI induced cytoprotective autophagy in bladder cancer cell lines T24 and BIU87. In addition, EPI robustly activated JNK-mediated phosphorylation of Bcl-2 and disruption of Bcl-2/Beclin-1 complex. Furthermore, the green tea derivative tea polyphenol (TP) inhibited EPI-induced autophagy and promoted apoptosis induced by EPI in bladder cancer cells. These results revealed a pathway for EPI-induced autophagy that involved in JNK/Bcl-2/Beclin-1 in bladder cancer cells, and that TP synergistically promoted EPI-induced apoptosis at least partly through autophagy inhibition. Thus, TP could be utilized in combination with EPI to improve EPI-based bladder cancer therapy.
\end{abstract}

Key words: autophagy, JNK, epirubicin, tea polyphenol, apoptosis

Human bladder cancer, one of the most commonly diagnosed urinary malignancies, was the fourth most prevalent cancer in men. It was estimated that there were 141,610 new cases of bladder cancer and 30,350 cancer related deaths in the United States [1]. While more early diagnosis methods and suitable surgeries for the patients with bladder cancer are emerged, the recurrence and mortality rate havenot been reduced effectively [2]. For those received transurethral resection, the recurrence rate within 5 years is as high as $50-70 \%$ [3]. The effect of postoperative perfusion chemotherapy plays a crucial role in suppressing recurrence and progress of bladder cancer. However, drug resistance becomes a significant obstacle to achieve a favorable prognosis. Therefore, searching for a novel and effective therapy to decrease recurrence and progress of bladder cancer is necessary.

Epirubicin (EPI) is an anthracycline drug that has been widely used for treating cancers including bladder cancer [4]. As a topoisomerase-II inhibitor, EPI causes apoptosis in cancer cells by inducing DNA damages [5]. However, drug resistance may suppress the therapy efficacy and worsen the prognosis of this disease. Thus, understanding the molecular mechanisms underlying the resistance to chemotherapy is essential for the development of novel treatment strategies for bladder cancer.

In breast cancer cells, EPI-based chemoresistance involves autophagy that protects cancer cells from cytotoxicity [6]. Autophagy is an evolutionarily conserved cellular process for degrading dysfunctional and damaged proteins and organelles and recycling the materials to provide the sources of energy in response to diverse stresses [7]. Studies demonstrated that the induction of autophagy plays a protective role in the resistance to anticancer drugs [8]. Furthermore, emerging evidence indicates that pharmacological or genetic inhibition of autophagy enhances apoptosis in cancer cells [9-11]. Therefore, autophagy plays an important role in chemotherapy resistance in cancer cells.

Tea polyphenols (TP), the major components of green tea extract, displays strong biological effects including antioxidant, anti-proliferation, anti-angiogenesis, anti-tumorigenesis and pro-apoptosis [12-14]. Moreover, several studies have reported that TP inhibits autophagy leading to apoptosis in mouse macrophages and human cancer cells [15-18]. In order to explore if TP can be used as a sensitizer for EPI, we tested the effects of the combination of EPI and TP in treating bladder cancer cells and explored the underlying mechanism. 


\section{Materials and methods}

Reagents and antibodies. Epirubicin hydrochloride (Pharmorubicin) was purchased from Pfizer (Jiangsu, China). Tea polyphenols (purity 98\%) was obtained from Shanghai Yuanye Biotechnology Co. Ltd. (Shanghai, China). Chloroquine (CQ) and 3-methyladenine (3-MA) was from Sigma-Aldrich (USA). SP, SB, U0126 were purchased from Selleckchem (USA).

Mouse anti ACTB was purchased from Zoonbio Biotechnology (Nanjing, China). Rabbit anti LC3B was from Sigma-Aldrich (USA). Mouse anti p62 and mouse anti PARP were from BD (USA). Mouse anti GAPDH was purchased from ZSGB Biotechnology (Beijing, China). Rabbit anti pJNK, mouse anti JNK1, rabbit anti Bcl-2, Rabbit anti Caspase 3 and mouse anti Beclin1 were obtained from Cell Signaling Technology (USA). The HRP-labeled goat anti rabbit and goat anti mouse were purchased from Boster Biotechnology Co. Ltd. (Wuhan, China).

Cell cultures. The bladder cancer cell line T24 and BIU87 were gifts from Chongqing Key Laboratory of molecular Oncology and Epigenetics (Chongqing, China) and were cultured in RPMI-1640 culture medium (Hyclone) with 10\% fetal bovine serum (FBS) at $37^{\circ} \mathrm{C}$ in a $5 \% \mathrm{CO}_{2}$ incubator. To investigate the effects of EPI and TP, various concentrations of EPI and TP were added into the culture medium for an indicated time period and then cells were harvested and analyzed.

Cell proliferation assay. The MTT assay was applied to evaluate the viability and proliferation of cells. A total of 8 $\mathrm{x} 10^{3}$ cells/well for T24 cells and $3 \times 10^{3}$ cells/well BIU87 cells were, respectively, seeded into a 96 -well plate and incubated in culture medium for $12 \mathrm{~h}$ at $37^{\circ} \mathrm{C}$. Then culture medium was replaced with fresh medium containing various concentrations of TP $(88.8,177.7,355.4,710.8,1421.6 \mu \mathrm{M})$ and EPI $(2.3,4.6,9.2,18.4,36.8 \mu \mathrm{M})$, and these cells were incubated for $24 \mathrm{~h}$. And then, cells of each well were added with $20 \mu \mathrm{l}$ of $5 \mathrm{mg} / \mathrm{ml} \mathrm{MTT}$ solution. After $4 \mathrm{~h}$ incubation at $37{ }^{\circ} \mathrm{C}$, the formazan crystals were dissolved by $150 \mu \mathrm{l}$ DMSO. The absorbance rate was measured at $570 \mathrm{~nm}$ by using a spectrophotometer (Thermo, USA). Each experiment was carried out in triplicates.

Annexin V/PI assay. T24 cells and BIU87 cells were plated at a density of $6 \times 10^{5}$ / well of 6 -well plates. After treatment as indicated as the figure legend, apoptotic cells were evaluated by Annexin V/P I staining (BD, USA) according to the manufacturer's instructions and then were measured by flow cytometry (BD, USA).

Electron microscopy. T24 cells and BIU87 cells were plated at a density of $6 \times 10^{5} /$ well of 6 -well plates. After treatment as indicated, cells were collected in Eppendorf tubes by centrifugation after being digested with $0.25 \%$ trypsin. And then cells were fixed with $4 \%$ glutaraldehyde and 1\% osmium tetraoxide overnight and embedded in epoxide resin, followed by ultrathin sections $(50 \mathrm{~nm})$ prepared on an ultramicrotome.
And next, ultrathin sections were double stained with uranyl acetated and lead citrate. Images of the autophagosome in cytoplasm were viewed with a transmission electron microscope (Olympus, Japan).

Western blot. After treatment as indicated, cells were collected and proteins were extracted in lysis buffer. After quantification by ultraviolet spectrophotometry, $30 \mu \mathrm{g}$ proteins in each lane were separated by SDS-PAGE (12\% gels), and electrophoretically transferred onto PVDF membranes. The membranes were blocked for $1 \mathrm{~h}$ in $5 \%$ non-fat milk in TBS/T and then incubated with various antibodies at $4{ }^{\circ} \mathrm{C}$ overnight. The next day, the membranes were washed three times for $10 \mathrm{~min}$, and then incubated in HRP-labeled secondary antibody, washed again three times for $10 \mathrm{~min}$, and finally exposed to enhanced chemiluminescence (ECL) detection reagents (Millipore) and photographed.

Statistical analysis. The SPSS19.0 was applied to carry out statistical analysis. All experiments were repeated at least three times. Quantitative data were shown as the mean \pm SE. Comparison of the effects of different treatments was performed using One-Way ANOVA analysis. Statistically significant differences between groups were analyzed using LSD-t-test. $\mathrm{P}<0.05$ was considered indicate a statistically significant result.

\section{Results}

TP potentiatesEPI-induced cytotoxicity in bladder cancer cells. The effects of EPI alone and in combination with TP on cell viability were examined in T24 and BIU87 cells. As shown in Figure $1 \mathrm{~A}$, the viability was inhibited in a dose-depending manner. The $\mathrm{IC}_{50}$ of EPI and TP were 8.6 and $399.6 \mu \mathrm{M}$ in T2 4 cells while 38.3 and $670.8 \mu \mathrm{M}$ in BIU87 cells. We chose EPI of $5 \mu \mathrm{M}$ and $20 \mu \mathrm{M}$ to treat T2 4 cells and BIU87 cells alone respectively for $24 \mathrm{~h}$ and in combination with TP of low toxic concentration $(100 \mu \mathrm{M})$. As shown in Figure $1 \mathrm{~B}$ and $1 \mathrm{C}$, viability inhibition by EPI was $40.33 \%$ and $38.09 \%$ in T24 cells and BIU87 cells, respectively. While TP had little effect alone, it strongly increased that of EPI in both T24 cells (80.42\%inhibition) and BIU87 cells $(73.19 \%$ inhibition). These results suggest that TP at a non-toxic concentration can augments EPI-induced viability inhibition in bladder cancer cells.

TP inhibits EPI-induced autophagy in bladder cancer cells. It has been reported that EPI induces autophagy in breast and liver cancer cells $[19,20]$. To investigate if EPI has the similar effect in bladder cancer cells, we examined autophagy activation markers in EPI-treated T24 and BIU87 cells. As shown in Figure 2A, LC3-II was significantly increased, while p62 was decreased in a time-dependent manner in both T24 cells and BIU87 cells, suggesting that autophagy was activated. To verify the results, autophagic flux was examined with lysosome inhibitor chloroquine (CQ). CQ inhibits LC-II degradation in autolysosomes, resulting in the accumulation of LC3-II [21]. While EPI 
A

B

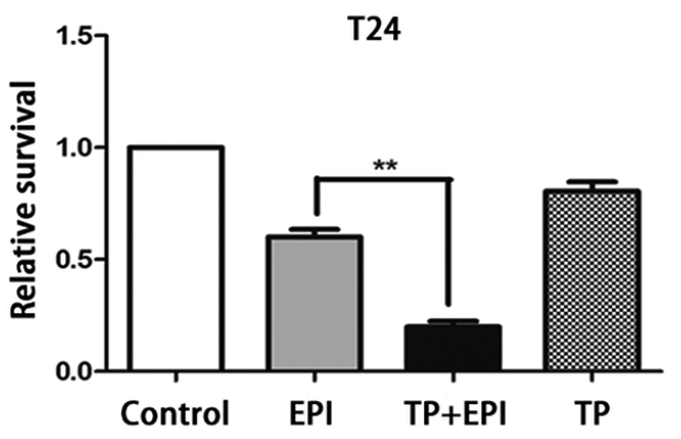

EPI

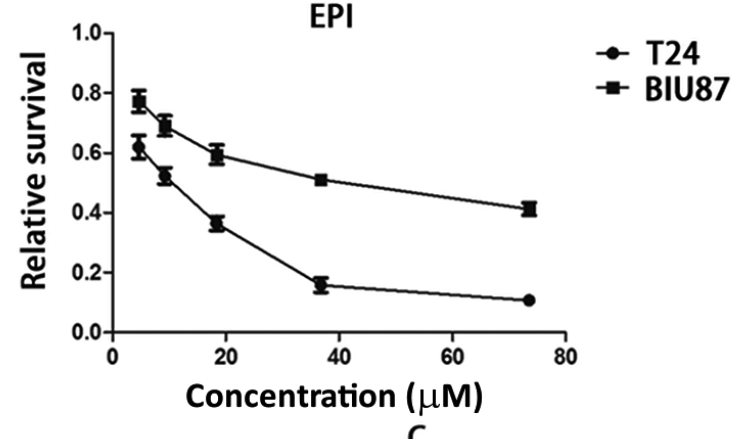

C

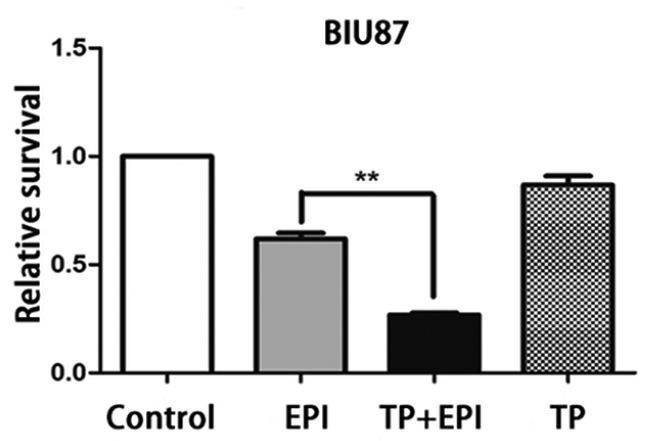

Figure 1. TP potentiates EPI-induced cytotoxicity in bladder cancer cells (A) T24 and BIU87 cells were exposed to EPI of indicated concentrations for $24 \mathrm{~h}$ and the cell viability was measured by MTT assay. (B and C) T24 cells were treated with blank, EPI (5 $\mu$ M), EPI (5 $\mu$ M) plus TP (100 $\mu$ M) and TP $(100 \mu \mathrm{M})$ and BIU87 cells were treated with blank, EPI $(20 \mu \mathrm{M})$, EPI $(20 \mu \mathrm{M})$ plus TP $(100 \mu \mathrm{M})$ and TP $(100 \mu \mathrm{M})$ for $24 \mathrm{~h}$. Cell viability was detected by MTT assay.

and CQ slightly increased LC3-II, the combination of both significantly increased the level of LC3-II, strongly suggest that EPI induced autophagy activation (Figure 2B). To explore if the EPI-induced autophagy could be inhibited by TP, we treated the cells with EPI and combined with TP. The induction of LC3-II by EPI was completely abolished in the EPI plus TP treated cells, indicating that the EPI-induced autophagy was inhibited by TP (Figure 2C). Furthermore, electron microscope was applied to observe the amount of autophagosome and autolysosome. As shown in Figure 2D, the amount of autophagic vesicles in both two cell lines treated with EPI plus TP was also reduced significantly compared with the cells treated with EPI alone. Taken together, these results suggest that TP inhibits EPI-induced autophagy in bladder cancer cells.

EPI activates autophagy through phosphorylation of JNK. In order to explore the mechanism by which EPI induces autophagy in bladder cancer cells, we investigated if JNK is involved [22]. Specific inhibitor against JNK, ERK and p38 were used to treat the cells. The JNK inhibitor SP remarkably reduced EPI-induced LC3-II levels, while the ERK and p38 inhibitors showed little effect (Figure 3A). Because JNK phosphorylates the pro-survival $\mathrm{Bcl}-2$ family proteins causing disruption of the complex of $\mathrm{Bcl}-2 / \mathrm{Beclin} 1$ to promote autophagy [22], we examined Bcl-2 in EPI-treated T24 and
BIU87 cells. As shown in Figure 3B, Bcl-2 was decreased in a time-dependent manner in both T24 and BIU87 cells. These results suggest that EPI-induced autophagy may involve the JNK/Bcl-2/Beclin1 pathway.

TP promotes EPI-induced apoptosis in bladder cancer cells. Since inhibition of autophagy could sensitize cancer cells to chemotherapeutic treatments through apoptosis [23, 24], we investigated whether combination of TP and EPI has effect on apoptosis in bladder cancer cells. Annexin V staining followed by cytometry was applied to measure apoptosis. As shown in Figure 4A, EPI alone induced apoptosis. The combination of EPI and TP significantly increased apoptosis. The apoptosis markers, cleavage of Caspase 3 and PARP were examined (Figure 4B). EPI alone induced cleavage of Caspase 3 and PARP, which was enhanced by TP. A similar enhancement of cleavage of Caspase 3 and PARP was also detected in the autophagy inhibitor 3MA and EPI treated cells (Figure 4B), suggesting that the effect of TP on EPI-induced apoptosis mainly depends on autophagy inhibition.

\section{Discussion}

In this study, we provided evidence that Epirubicin induced autophagy in human bladder cancer cells, which can be inhibited by tea polyphenols. EPI strongly activated JNK 
and decreased $\mathrm{Bcl}-2$ expression, suggesting that EPI-induced autophagy involves the JNK/Bcl-2/Beclin-1 signaling cascade. Furthermore, we found that, similar to the autophagy inhibitor 3MA, TP potentiated EPI-induced apoptosis. Altogether, our results suggest that TP may be used in combination with anti-cancer agent EPI to improve the therapy efficacy against bladder cancer.

EPI is routinely used in the postoperative perfusion chemotherapy to prevent bladder cancer recurrence. However, resistance to EPI becomes a serious problem [3]. As reported in recent studies, autophagy contributes to resistance to anticancer treatment in cancer cells $[25,26]$. Whether and how EPI induces autophagy in bladder cancer cells are still elusive. In this study we first investigated whether EPI is able to induce autophagy in bladder cancer cells. The results with the induction of LC3-II increase and p62 decrease, particularly autophagic flux, by EPI clearly show that EPI activates autophagy in bladder cancer cells. In addition, we found that the JNK was activated by EPI. JNK is one of the MAP kinases that are involved in autophagy regulation [27-29]. In this study, we found that inhibition of the JNK, but not ERK and p38, effectively suppressed EPI-induced autophagy, suggesting that JNK is involved in EPI-induced autophagy in bladder cancer cells. As reported previously [22, 29, 30], JNK activation leads to phosphorylation or degradation of $\mathrm{Bcl} 2$, which suppress the Bcl-2/Beclin-1 complex to release the brake on Beclin-1-mediated autophagy activation. Therefore, it is likely that EPI-induced autophagy involves the JNK/Bcl-2/ Beclin-1 signaling cascade and targeting this pathway may be utilized for modulating autophagy-mediated chemoresistance in EPI-based anticancer treatment.

Deriving from green tea, TP displays strong preventive effects against cancer [31]. TP has been shown to synergistically sensitize anticancer agents in killing cancer cells through inhibiting autophagy and promoting apoptosis $[17,32]$. In the present study, we investigated the effect of TP on EPI's anticancer activity in bladder cancer cells. The results showed that TP inhibited EPI-induced autophagy in bladder cancer cells. However, it is noteworthy that TP was shown to promote autophagy induction in vascular endothelial cells in a previous report [33], which is inconsistent with our results. The reason of this discrepancy is currently unknown but is likely due to different cell context. It is also possible to be due to different concentrations of TP used.TP stimulates autophagy at the concentration of $10 \mu \mathrm{M}$, while at a higher concentration $(100 \mu \mathrm{M})$, it mainly inhibits autophagy induced by EPI. In spite of TP's different functions at different concentrations, our results clearly suggested that TP suppresses EPI-induced autophagy in human bladder cancer cells.

While our data show that TP inhibited EPI-induced autophagy, the mechanism is not fully understood. Unfortunately, we found that TP could not reverse EPI-induced JNK activation and Bcl-2 degradation (Data not shown).
A
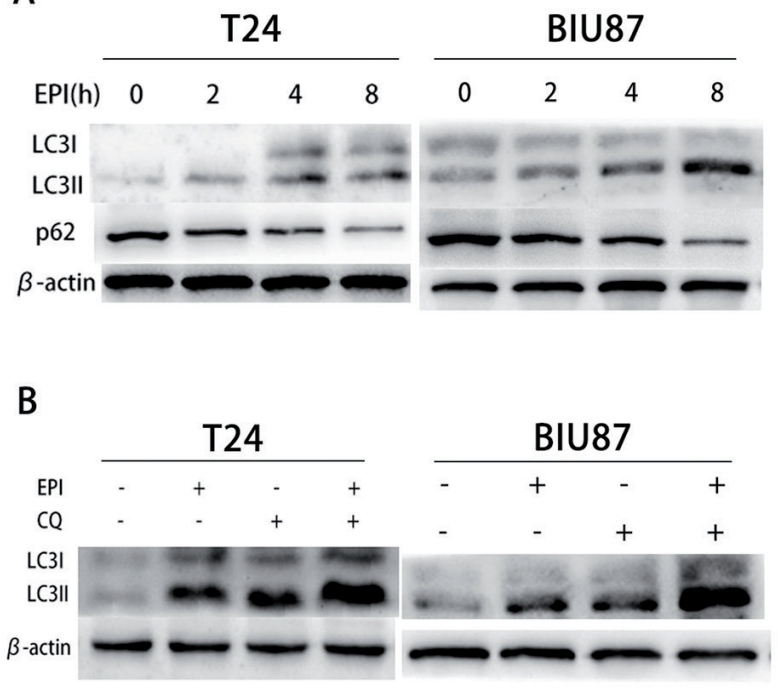

\section{C}
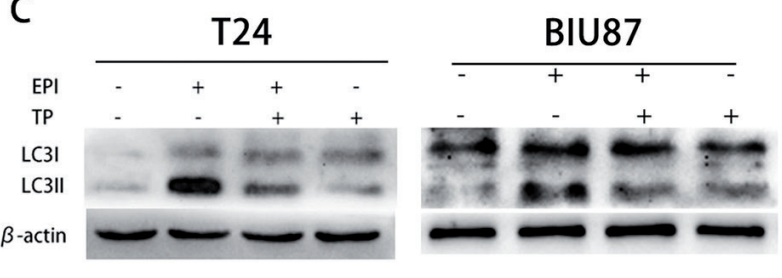

D
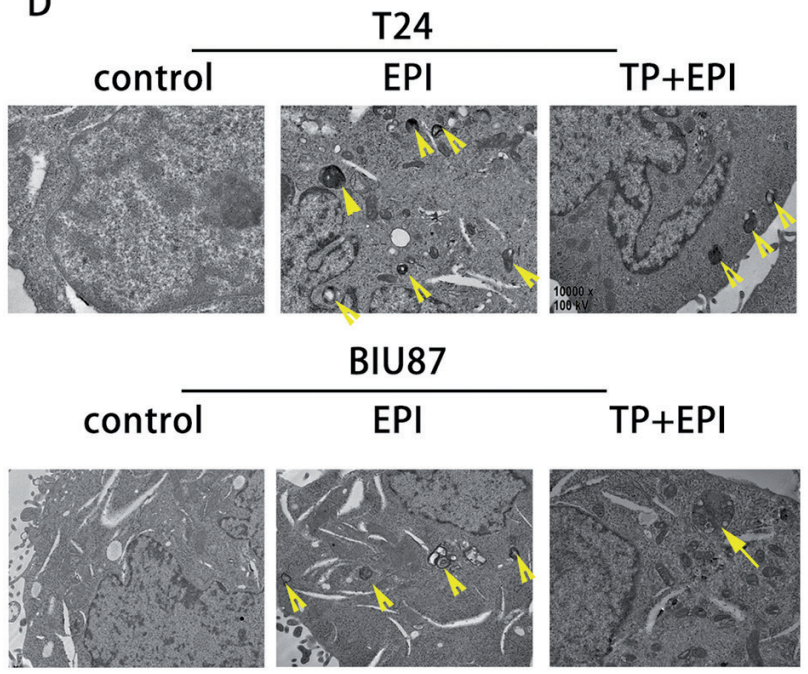

Figure 2. TP inhibits EPI-induced autophagy in bladder cancer cells (A) T24 and BIU87 cells were treated with EPI $(5 \mu \mathrm{M}$ for T24 and $20 \mu \mathrm{M}$ for BIU87) for indicated times. The indicated proteins were detected by western blot. (B) The cells were pretreated with chloroquine (CQ, $20 \mu \mathrm{M})$ for $30 \mathrm{~min}$ and then treated with EPI $(5 \mu \mathrm{M}$ for T24 and $20 \mu \mathrm{M}$ for BIU87) for an additional $4 \mathrm{~h}$. The indicated proteins were detected by western blot. (C) The cells were pretreated with $\mathrm{TP}(100 \mu \mathrm{M})$ for 30 min and then treated with EPI ( $5 \mu \mathrm{M}$ for T24 and $20 \mu \mathrm{M}$ for BIU87) for an additional $4 \mathrm{~h}$. The indicated proteins were detected by western blot. (D) T24 and BIU87 cells were pretreated with TP $(100 \mu \mathrm{M})$ for $30 \mathrm{~min}$ and then treated with EPI ( $5 \mu \mathrm{M}$ for T24 and $20 \mu \mathrm{M}$ for BIU87) for an additional $4 \mathrm{~h}$. Autophagosomes were viewed by transmission electron microscope. The arrows indicate autophagosomes. 
A
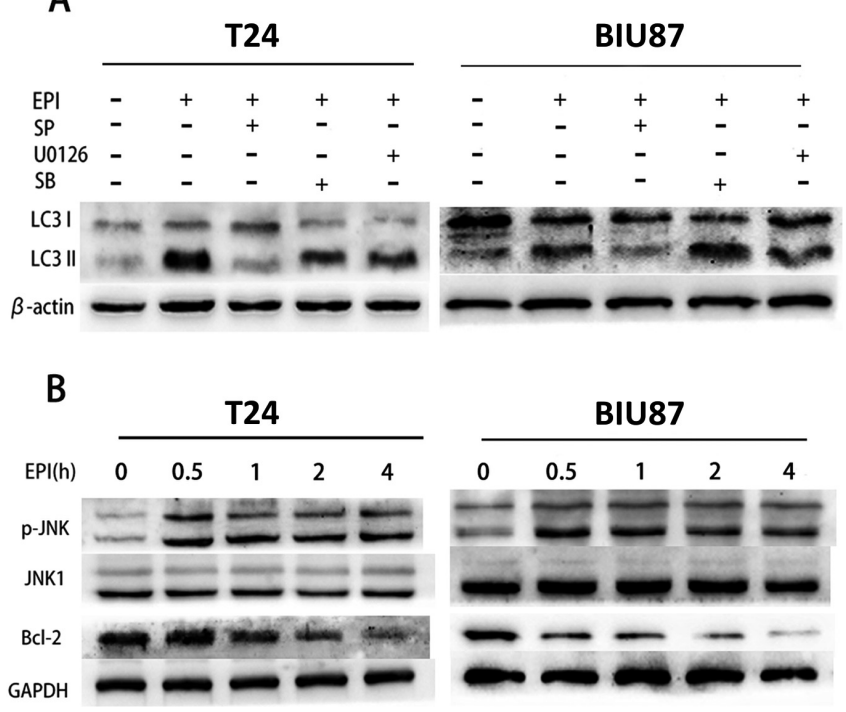

Figure 3. EPI activates autophagy through phosphorylation of JNK (A) T24 and BIU87 cells were pretreated with different inhibitors (SP600125, $10 \mu \mathrm{M}$; SB203580, $10 \mu \mathrm{M}$; U0126, $10 \mu \mathrm{M}$ ) for $30 \mathrm{~min}$ and then treated with EPI ( $5 \mu \mathrm{M}$ for T24 and $20 \mu \mathrm{M}$ for BIU87) for an additional $4 \mathrm{~h}$. The indicated proteins were detected by western blot. (B) T24 and BIU87 cells were treated with EPI ( $5 \mu \mathrm{M}$ for T24 and $20 \mu \mathrm{M}$ for BIU87) for indicated times. The indicated proteins were detected by western blot.

Chemotherapy induced autophagy may involve HMGB1, a chromatin-associated nuclear protein that translocates into cytoplasm to bind Beclin-1. Dissociating Beclin-1/Bcl2 complex by HMGB1 initiates autophagy [34]. Moreover, emerging evidence indicates that TP inhibits the translocation of HMGB1 [35], suggesting that HMGB1 might be involved in TP's inhibition on EPI-induced autophagy in bladder cancer cells. Further investigations are needed to address this question.

In summary, our results suggest that a pathway consisting of JNK/Bcl-2/Beclin-1 is involved in EPI-induced autophagy in bladder cancer cells. TP can inhibit EPI-induced autophagy to potentiate EPI-induced apoptosis. Our study suggests that a novel strategy with combination of TP and EPI maybe used to improve the efficacy of bladder cancer therapy, which may also shed lights on the application of TP in other clinical fields.

Acknowledgments: The authors declare no conflict of interest. This work was supported by a Grant from National Natural Science Foundation of China (No.81372758).

\section{References}

[1] SIEGEL R, MA J, ZOU Z, JEMAL A. Cancer statistics, 2014. CA Cancer J Clin 2014; 64: 9-29. https://doi.org/10.3322/ caac. 21208
A
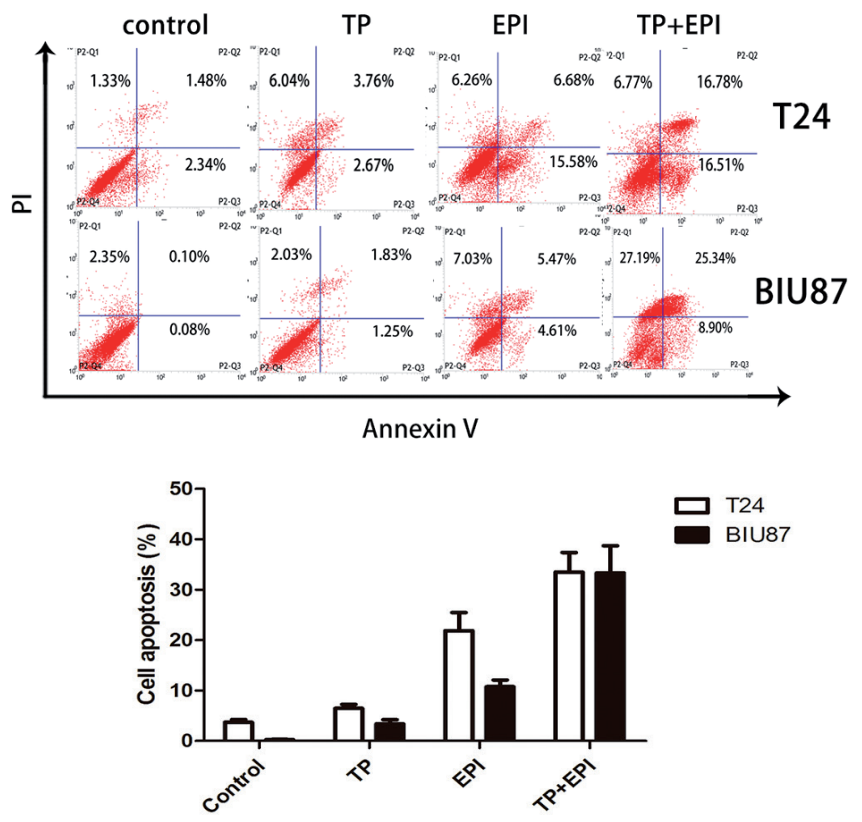

B

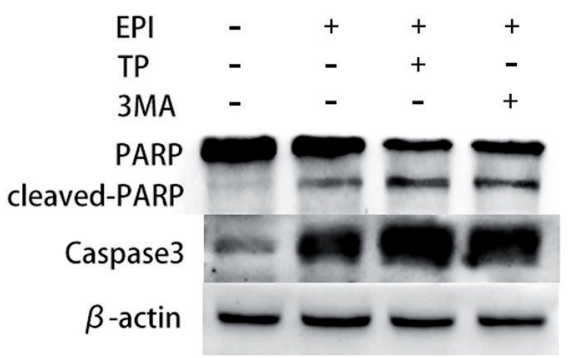

Figure 4. TP promotes EPI-induced apoptosis in bladder cancer cells (A) T24 and BIU87 cells were pretreated with TP $(100 \mu \mathrm{M})$ for $30 \mathrm{~min}$ and then treated with EPI ( $5 \mu \mathrm{M}$ for T24 and $20 \mu \mathrm{M}$ for BIU87) for an additional $24 \mathrm{~h}$. Cell apoptosis levels were evaluated by flow cytometry. Annexin V+/PI- represents the early apoptotic stage, whereas Annexin $\mathrm{V}+/ \mathrm{PI}+$ represents apoptotic cells in the terminal stage. Annexin V-/PI+ stands for necrotic cells. The percentages of early and terminal stage apoptotic cells were calculated and are shown in the histogram. (B) T24 cell was pretreated with TP $(100 \mu \mathrm{M})$ or $3 \mathrm{MA}(1 \mathrm{mM})$ for $30 \mathrm{~min}$ and then treated with EPI $(5 \mu \mathrm{M})$ for $24 \mathrm{~h}$. The indicated proteins were detected by western blot.

[2] KIM WJ, BAE SC. Molecular biomarkers in urothelial bladder cancer. Cancer Sci 2008; 99: 646-652. https://doi. org/10.1111/j.1349-7006.2008.00735.X

[3] PAN XW, LI L, HUANG Y, HUANG H, XU DF et al. Icaritin acts synergistically with epirubicin to suppress bladder cancer growth through inhibition of autophagy. Oncology Rep 2016; 35: 334-342.

[4] ONRUST SV, WISEMAN LR, GOA KL. Epirubicin: a review of its intravesical use in superficial bladder cancer. Drugs Aging 1999; 15: 307-333. https://doi.org/10.2165/00002512199915040-00006 
[5] CHANG WT, CHENG HL, HSIEH BS, CHIU CC, LEE KT et al. Progesterone increases apoptosis and inversely decreases autophagy in human hepatoma HA22T/VGH cells treated with epirubicin. ScientificWorldJournal 2014; 2014: 567148. https://doi.org/10.1155/2014/567148

[6] SUN WL, CHEN J, WANG YP, ZHENG H. Autophagy protects breast cancer cells from epirubicin-induced apoptosis and facilitates epirubicin-resistance development. Autophagy 2011; 7: 1035-1044. https://doi.org/10.4161/ auto.7.9.16521

[7] MIZUSHIMA N, KOMATSU M. Autophagy: renovation of cells and tissues. Cell 2011; 147: 728-741. https://doi. org/10.1016/j.cell.2011.10.026

[8] LIU L, YANG M, KANG R, WANG Z, ZHAO Y et al. HMGB1-induced autophagy promotes chemotherapy resistance in leukemia cells. Leukemia 2011; 25: 23-31. https://doi. org/10.1038/leu.2010.225

[9] CHEN X, TAN M, XIE Z, FENG B, ZHAO Z et al. Inhibiting ROS-STAT3- dependent autophagy enhanced capsaicin-induced apoptosis in human hepatocellular carcinoma cells. Free Rad Res 2016; 50: 744-755. https://doi.org/10.3109/10715762 .2016 .1173689

[10] CAO X, LIU B, CAO W, ZHANG W, ZHANG F et al. Autophagy inhibition enhances apigenin-induced apoptosis in human breast cancer cells. Chin J Cancer Res 2013; 25: 212-222.

[11] TANG Q, LI G, WEI X, ZHANG J, CHIU JF et al. Resveratrolinduced apoptosis is enhanced by inhibition of autophagy in esophageal squamous cell carcinoma. Cancer Lett 2013; 336: 325-337. https://doi.org/10.1016/j.canlet.2013.03.023

[12] YANG CS, WANG X. Green tea and cancer prevention. Nutr Cancer 2010; 62: 931-937. https://doi.org/10.1080/01635581. 2010.509536

[13] THAKUR VS, GUPTA K, GUPTA S. Green tea polyphenols causes cell cycle arrest and apoptosis in prostate cancer cells by suppressing class I histone deacetylases. Carcinogenesis 2012; 33: 377-384. https://doi.org/10.1093/carcin/bgr277

[14] KHAN N, ADHAMI VM, MUKHTAR H. Review: green tea polyphenols in chemoprevention of prostate cancer: preclinical and clinical studies. Nutr Cancer 2009; 61: 836-841. $\underline{\text { https:// }}$ doi.org/10.1080/01635580903285056

[15] HASHIMOTO K, SAKAGAMI H. Induction of apoptosis by epigallocatechin gallate and autophagy inhibitors in a mouse macrophage-like cell line. Anticancer Res 2008; 28: $1713-1718$.

[16] ZHANG Y, YANG ND, ZHOU F, SHEN T, DUAN T et al. (-)-Epigallocatechin-3-gallate induces non-apoptotic cell death in human cancer cells via ROS-mediated lysosomal membrane permeabilization. PLoS One 2012; 7: e46749. https://doi.org/10.1371/journal.pone.0046749

[17] LIU J, TANG Y, FENG Z, LIU J, LIU J, et al. (-)-Epigallocatechin-3-gallate attenuated myocardial mitochondrial dysfunction and autophagy in diabetic Goto-Kakizaki rats. Free Radic Res 2014; 48: 898-906. https://doi.org/10.3109/1 $\underline{0715762.2014 .920955}$

[18] LIU J, TANG Y, FENG Z, HOU C, WANG H et al. Acetylated FoxO1 mediates high-glucose induced autophagy in H9c2 cardiomyoblasts: regulation by a polyphenol -(-)-epigallocatechin-3-gallate. Metabolism 2014; 63: 1314-1323. https:// doi.org/10.1016/j.metabol.2014.06.012

[19] CHITTARANJAN S, BORTNIK S, DRAGOWSKA WH, XU J, ABEYSUNDARA $N$ et al. Autophagy inhibition augments the anticancer effects of epirubicin treatment in anthracycline-sensitive and -resistant triple-negative breast cancer. Clin Cancer Res 2014; 20: 3159-3173. https://doi. org/10.1158/1078-0432.CCR-13-2060

[20] PENG W, DU T, ZHANG Z, DU F, JIN J et al. Knockdown of autophagy-related gene LC3 enhances the sensitivity of HepG cells to epirubicin. Exp Ther Med 2015; 9: 1271-1276.

[21] KLIONSKY DJ, ABDALLA FC, ABELIOVICH H, ABRAHAM RT, ACEVEDO-AROZENA A et al. Guidelines for the use and interpretation of assays for monitoring autophagy. Autophagy 2012; 8: 445-544. https://doi.org/10.4161/ auto. 19496

[22] WEI Y, PATTINGRE S, SINHA S, BASSIK M, LEVINE B. JNK1-mediated phosphorylation of $\mathrm{Bcl}-2$ regulates starvation-induced autophagy. Mol Cell 2008; 30: 678-688. https://doi.org/10.1016/j.molcel.2008.06.001

[23] XIE JM, LI B, YU HP, GAO QG, LI W et al. TIGAR has a dual role in cancer cell survival through regulating apoptosis and autophagy. Cancer Res 2014; 74: 5127-5138. https://doi. org/10.1158/0008-5472.CAN-13-3517

[24] CHEN WC, HSU KY, HUNG CM, LIN YC, YANG NS et al. The anti-tumor efficiency of pterostilbene is promoted with a combined treatment of Fas signaling or autophagy inhibitors in triple negative breast cancer cells. Food Funct 2014; 5: 1856-1865. https://doi.org/10.1039/C4FO00145A

[25] ZHANG LH, YANG AJ, WANG M, LIU W, WANG CY et al. Enhanced autophagy reveals vulnerability of P-gp mediated epirubicin resistance in triple negative breast cancer cells. Apoptosis 2016; 21:473-488. https://doi.org/10.1007/s10495016-1214-9

[26] SUN WL, LAN D, GAN TQ, CAI ZW. Autophagy facilitates multidrug resistance development through inhibition of apoptosis in breast cancer cells. Neoplasma 2015; 62: 199-208. https://doi.org/10.4149/neo 2015025

[27] MATSUZAWA T, KIM BH, SHENOY AR, KAMITANI S, MIYAKE $\mathrm{M}$ et al. IFN-gamma elicits macrophage autophagy via the p38 MAPK signaling pathway. J Immunol 2012; 189: 813-818. https://doi.org/10.4049/jimmunol.1102041

[28] CAGNOL S, CHAMBARD JC. ERK and cell death: mechanisms of ERK-induced cell death--apoptosis, autophagy and senescence. FEBS J 2010; 277: 2-21. https://doi.org/10.1111/ j.1742-4658.2009.07366.x

[29] HE W, WANG Q, SRINIVASAN B, XU J, PADILLA MT et al. A JNK-mediated autophagy pathway that triggers c-IAP degradation and necroptosis for anticancer chemotherapy. Oncogene 2014; 33: 3004-3013. https://doi.org/10.1038/ onc. 2013.256

[30] HE W, WANG Q, XU J, XU X, PADILLA MT et al. Attenuation of TNFSF10/TRAIL-induced apoptosis by an autophagic survival pathway involving TRAF2- and RIPK1/RIP1-mediated MAPK8/JNK activation. Autophagy 2012; 8: 1811-1821. https://doi.org/10.4161/auto.22145 
[31] LAMBERT JD. Does tea prevent cancer? Evidence from laboratory and human intervention studies. Am J Clin Nutr 2013; 98: 1667s-1675s. https://doi.org/10.3945/ ajcn.113.059352

[32] CHEN L, YE HL, ZHANG G, YAO WM, CHEN XZ et al. Autophagy inhibition contributes to the synergistic interaction between EGCG and doxorubicin to kill the hepatoma Hep3B cells. PLoS One 2014; 9: e85771. https://doi.org/10.1371/ journal.pone.0085771

[33] KIM HS, MONTANA V, JANG HJ, PARPURA V, KIM JA. Epigallocatechin gallate (EGCG) stimulates autophagy in vascular endothelial cells: a potential role for reducing lipid accumulation. J Biol Chem 2013; 288: 22693-22705. https:// doi.org/10.1074/jbc.M113.477505

[34] KANG R, LIVESEY KM, ZEH HJ, LOZE MT, TANG D. HMGB1: a novel Beclin 1-binding protein active in autophagy. Autophagy 2010; 6: 1209-1211. https://doi.org/10.4161/ auto.6.8.13651

[35] LI W, ASHOK M, LI J, YANG H, SAMA AE et al. A major ingredient of green tea rescues mice from lethal sepsis partly by inhibiting HMGB1. PLoS One 2007; 2: e1153. https://doi. org/10.1371/journal.pone.0001153 